\title{
Psychological Treatment of Psychosis
}

DOI:

10.1002/9781444327298.ch32

Link to publication record in Manchester Research Explorer

\section{Citation for published version (APA):}

Haddock, G., \& Spaulding, W. (2011). Psychological Treatment of Psychosis. In Schizophrenia: Third Edition/Schizophrenia: Third Ed. (pp. 666-686). John Wiley \& Sons Ltd.

https://doi.org/10.1002/9781444327298.ch32

\section{Published in:}

Schizophrenia: Third Edition|Schizophrenia: Third Ed.

\section{Citing this paper}

Please note that where the full-text provided on Manchester Research Explorer is the Author Accepted Manuscript or Proof version this may differ from the final Published version. If citing, it is advised that you check and use the publisher's definitive version.

\section{General rights}

Copyright and moral rights for the publications made accessible in the Research Explorer are retained by the authors and/or other copyright owners and it is a condition of accessing publications that users recognise and abide by the legal requirements associated with these rights.

\section{Takedown policy}

If you believe that this document breaches copyright please refer to the University of Manchester's Takedown Procedures [http://man.ac.uk/04Y6Bo] or contact uml.scholarlycommunications@manchester.ac.uk providing relevant details, so we can investigate your claim.

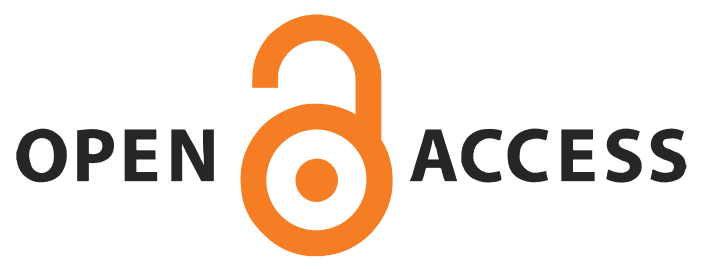




\title{
Psychological treatment of psychosis
}

\author{
Gillian Haddock ${ }^{*}$ \\ University of Manchester, UK
}

\author{
And \\ Will Spaulding \\ University of Nebraska, Lincoln, USA
}

\begin{abstract}
For: Schizophrenia: $3^{\text {rd }}$ edition
Keywords: cognitive-behaviour therapy, family intervention, neuropsychological therapy, social skills training, dual disorders. schizophrenia
\end{abstract}

\author{
${ }^{*}$ Address for correspondence \\ Professor Gillian Haddock \\ School of Psychological Sciences \\ University of Manchester \\ Zochonis Building \\ Manchester M15 6SZ
}




\begin{abstract}
Psychological treatments for the treatment of psychosis have been widely studied over many years. Early studies were mainly in the form of individual case studies or case series. However, more recently, treatments have been evaluated in larger, controlled trials leading to a larger evidence base on which to judge their effectiveness for psychosis. This evidence bases suggests that certain approaches can be effective in reducing the severity and distress associated with psychosis and some of these have become more widely employed in the treatment of severe mental health problems over the last decade in the United Kingdom, Europe and the United States. Generally, the treatments with the greatest evidence base are in following treatment domains: 1) individual cognitive and behavioural therapies for psychosis, 2) family interventions for psychosis, 3) neuropsychological and cognitive remediation approaches, 4) social skills training and other skills training approaches and 5) contingency management approaches. Characteristics of the approaches are described, (using clinical examples) and evidence in support of their effectiveness is presented. The implications for applying the approaches with complex cases, such as those with dual diagnoses is described. Finally, the challenges facing services in implementing the approaches is discussed.
\end{abstract}




\section{INTRODUCTION}

Psychological approaches in the management of mental health problems has become well established as a treatment approach for many disorders throughout the developed world. For many psychological complaints, for example, anxiety and depressive disorders, psychological treatments can be the first line treatment. Psychological treatment of psychotic disorders has received less attention in the literature, despite being applied to psychotic disorders for many years. For example, Bleuler (1911/1950) advocated the use of psychotherapies with people with schizophrenia and this has been supported by a number of other clinicians over the whole of the $20^{\text {th }}$ century (e.g. Beck, 1952; Sullivan, 1962). Aaron T. Beck, the, often described, 'father' of cognitive therapy, published a case study in 1952 describing a successful treatment of a young man with a delusional disorder using psychological approaches. Since that time, there have been a large number of published reports on psychological treatments for psychosis. During the first few decades of the twentieth century, these tended to be in the form of case study or case series reports rather than controlled trials like those designed to evaluate the effectiveness of drug treatments. However, over the last twenty to thirty years, there has been a growing body of well carried out, controlled research describing and evaluating psychological treatments for psychosis suggesting that these have an important place in the management of such disorders. In addition, government legislation is endorsing the use of psychological approaches in the management of psychosis, for example, the 
National Institute of Clinical Effectiveness in the United Kingdom makes the following recommendation

'Psychological treatments should be an indispensable part of the treatment options available for service users and their families in the effort to promote recovery. Those with the best evidence of effectiveness are cognitive behavioural therapy and family interventions. These should be used to prevent relapse, to reduce symptoms, increase insight and promote adherence to medication.' (NICE guidelines, 1.4.4, Department of Health, 2007).

In the United States, a renewed interest in psychological treatments is associated with the recovery movement, a growing consensus that recovery from mental illness must include more than suppression of symptoms. In 2004, a Presidential Commission (President's New Freedom Commission on Mental Health, 2004) sounded a keynote for this movement, setting in motion a massive reform of the federal mental health infrastructure, including the Veterans Administration (one of the largest healthcare organizations in the world) and the Substance Abuse and Mental Health Services Administration (SAMSHA). SAMSHA has developed a set of "toolkits," packaged materials for disseminating evidence-based treatment and rehabilitation modalities that are largely psychological in nature (SAMSHA, 2004). The American Psychological Association's Task Force on Serious Mental IIIness and Severe Emotional Disturbance (2007) has compiled a guide to evidence-based practices pertinent to schizophrenia and related disorders, along with resources for staff training and 
programme development, compromised primarily of psychological treatment approaches.

\section{PSYCHOLOGICAL TREATMENT APPROACHES IN SCHIZOPHRENIA}

Psychological interventions in psychosis have been influenced by a range of theoretical schools such as the psychoanalytic field, the literature on psychopathological processes in schizophrenia and the behavioural school and learning theory. These influences have guided and contributed to the development of psychological approaches over the last 100 years. Psychoanalytical approaches to the treatment of psychosis have not been evaluated widely or systematically and there is very little evidence that this type of approach can be helpful in the treatment of psychosis. Past reviewers of psychodynamic approaches for the treatment of psychosis have varied in their conclusions, with some authors suggesting that this type of approach has a place in the treatment of psychosis despite this conclusion being based on very little evidence (Huxley et al, 2000). Other authors have concluded that psychodynamic psychotherapy is clearly not effective in schizophrenia and that it may possibly be unhelpful (Mueser and Berenbaum, 1990). Paley and Shapiro (2002), when discussing the relative merits of different types of therapy in the treatment of psychosis argue that there may be an 'equivalence paradox' in relation to outcome from therapy across disorders i.e. that different therapies generally produce equivalent outcomes. They present this as support for the idea that different therapies, for example, psychodynamic psychotherapy need more 
evaluation before discounting them as potential treatments for psychosis. However, given that there has been very little pilot evidence to suggest that psychodynamic psychotherapy is helpful in psychosis, there is no good rationale for large investments in evaluation of the approach given it is not likely to offer any advantages to other, well evaluated interventions that are already available (Tarrier, Barrowclough, Haddock and Wykes, 2002).

Due to the limited evidence base for many interventions and the findings that some approaches have limited applicability in this area, the rest of this chapter will focus on the areas where there is a good supporting evidence base. These fall under the following headings:

1. Individual cognitive and behavioural therapies (CBT) for psychosis

2. Family interventions for psychosis

3. Neuropsychological and cognitive remediation approaches

4. Social skills training and other skills training approaches

5. Contingency management

6. Dealing with co-morbid disorders

Each of these areas will be discussed in turn.

\section{Individual cognitive and behavioural therapies for psychosis}

One area that has received much attention in the psychological treatment of psychosis is the cognitive-behavioural therapy approach. This approach has a long history of use in the treatment of psychotic disorders, highlighted by the case study by Beck in 1952 described above. Since that early case study, there 
has been a wealth of descriptions of interventions, usually focused on the remediation of particular psychotic symptoms i.e. hallucinations, delusions or negative symptoms. Early approaches were influenced more by the strictly behavioural psychology school, such as the use of contingency or reward approaches for reducing the occurrence of particular target behaviours (Nydegger, 1972; Haynes and Geddy, 1973), distraction procedures (Margo, Hemsley and Slade, 1981; James, 1983; Nelson et al, 1991), thought stopping (Samaan, 1975; Allen et al, 1983; ) and the use of aversion therapy (Alford and Turner, 1976, Turner, Hersen and Bellack, 1977). Whilst, successful reduction in the occurrence of target behaviours were frequently reported using these approaches, there was little evaluation of this type of approach in larger controlled trials and little evidence that the approaches generalised across situations or people (also see later section on contingency management). These approaches highlighted researcher's and clinician's emphasis on the removal of psychotic symptoms and the notion that symptoms of psychosis were 'ununderstandable' phenomena and were therefore not likely to respond to reason or discussion. (Jaspers, 1963). However, this notion of the 'ununderstandability' of psychotic symptoms has been much disputed by both psychopathology researchers and service users in more recent years resulting in a greater understanding of the development and maintenance of psychotic symptoms. For example, the application of effective techniques to help individuals test out the reality of delusional beliefs (e.g. Chadwick and Lowe, 1990) has demonstrated that, contrary to Jaspers earlier assertion, these beliefs 
do indeed respond to reason and are often understandable when considered in relation to the individual's beliefs and life experiences (Garety and Hemsley, 1997). In addition, the growing interest in 'talking' therapies for the treatment of other disorders e.g. cognitive therapy for anxiety and depression, as well as the greater interest in understanding the nature of particular psychotic symptoms led to the development of psychological approaches that involved exploring and treating psychotic phenomena in one to one talking therapies. This heralded the development of cognitive-behavioural treatments for psychotic disorders which lent themselves well to evaluation in larger controlled trials of their effectiveness. CBT has been applied to all phases of the disorder i.e. acute and recent onset psychosis (Lewis et al, 2002; Garety et al, 2007) and chronic and treatment resistant psychosis (Tarrier et al, 1998; Sensky et al, 2000). In addition, CBT has also been shown to be effective at reducing the transition to full-blown psychosis in those people experiencing pre-psychotic or high risk for psychosis states (Morrison et al, 2004), and has been used with people who are experiencing comorbid or dual disorders (see below) and to increase adherence to anti-psychotic medication (Kemp et al, 1996).

Cognitive behaviour therapy (CBT) treatment programme $\mathrm{CBT}$ is a one to one therapy, which is carried out in a collaborative fashion led by a shared agenda agreed between the therapist and individual. The approach assumes that the key problems of the client or patient (regardless of whether their origin is biological or otherwise) develop and are maintained by cognitive (thoughts and beliefs), physiological (emotional reactions) and behavioural 
factors and that these factors are ones that can be modified and influenced using psychological means. The therapy is individualised to the person's needs although it usually contains some basic, common elements. Therapy typically lasts for between twelve and thirty sessions (although this may need to be longer for some individuals) over a period of six to twelve months. Therapy sessions would usually last for between 30 and 60 minutes although flexibility is required to ensure that the session length is suitable matched to the individual's concentration and other cognitive abilities. Therapy tends to consist of four main stages: 1) engagement and socialisation into the model, 2) assessment and formulation of key problems, 3) intervention strategies to reduce severity and distress, and 4) consolidation of the benefits obtained during therapy and strategies to enhance staying well.

1. Engagement and socialisation to the model The nature of cognitive behaviour therapy is collaborative and based on a shared agenda between the therapist and individual. As a result, the first part of therapy involves engaging the individual in the approach. This phase is crucial to being able to use the approach and is likely to vary from person to person. Many people are keen and interested to engage in an approach which encourages them to discuss and reflect on their psychotic experiences; other therapeutic approaches that they have experienced may have discouraged or even provided negative feedback for doing so. Other individuals may be more sceptical of talking therapies or their symptoms may interfere with their ability to engage. For example, some psychotic experiences may considerably influence an individual's 
cognitive functioning such that they are not able to concentrate for more than a few moments or the severity or intrusiveness of their symptoms interferes with their ability to engage in interpersonal relationships required in therapy. Some people experiencing extremely acute psychotic symptoms may find that the intrusiveness of their experiences may interfere with their ability to engage in therapy and may be more likely to benefit at a later stage. Nevertheless, there is evidence that people with psychosis can engage in CBT regardless of the stage of illness or the acuteness of their symptoms, so no assumptions should be made about who would be most likely to engage. Several strategies can be taken to maximise the possibility of engagement such as being cognisant of the cognitive processing difficulties the patient may be experiencing, by being aware of where delusional or other psychotic beliefs may be influencing the person's ability to engage and by being aware of the possible mismatch between therapist and patient as to whether treatment using this approach is either helpful or necessary. Specific therapeutic strategies can assist with the engagement process. For example, where cognitive processing of information is a problem, the therapist should ensure that sessions are short and frequent and contain multiple summaries of information to ensure the individual is able to process the information. Where the patient does not recognise the need for, or importance of, treatment, motivational interviewing strategies (Miller and Rollnick, 2002; see also under section on co-morbid disorders below) may be helpful to clarify the patient's key values and goals. This may lead to recognition as to how therapy may help them to realise those goals. This type of approach can also be helpful 
in addressing issues relating to motivation to adhere to medication and to address problems with substance use (see below).

Until an individual is fully engaged in the approach, it is unlikely to be helpful to persist with therapy. A key marker for moving into the assessment phase is when the therapist is aware that the patient is willing to continue with therapy and has identified some key, shared problems and goals on which to work on in therapy. This will then provide the basis for future therapy sessions. 2. Assessment and formulation of key problems These sessions typically involve a therapist assessing and gaining an understanding of the individual's main problems. This may take one or more sessions (typically three to four) and culminates in the therapist and individual producing a shared description or formulation of the key problems that are described in relation to the way the problems have developed and are being maintained in relation to their key thinking patterns and beliefs (cognition), emotional responses and behaviour patterns.

Assessment approaches

The use of assessment tools in psychosis if often, largely, for diagnostic purposes, aimed at eliciting and measuring symptoms in terms of their presence or absence or severity i.e. different dimensions have been aggregated into a global, unidimensional representation of 'severity' (see the Brief Psychiatric Rating Scale; Overall and Gorham, 1962 or the Positive and Negative Syndrome Schedule; Kay et al, 1989). This type of assessment has been driven by the degree of information which is necessary to establish diagnosis in relation to prescribing drug treatment 
rather than being intended for driving psychological interventions. Cognitivebehavioural treatments may be directed towards individuals who have a similar diagnosis, such as schizophrenia but are not generally directed towards treating the whole 'syndrome'. CBT is usually aimed at eliciting the symptoms associated with a particular diagnosis and assessing the behavioural and cognitive correlates of these symptoms. It is then towards these correlates that treatment is directed. As a result, although diagnostic instruments can be invaluable in improving reliability in diagnosis and for eliciting symptoms, they are not primarily designed to provide sufficient information for cognitive-behaviour therapists to formulate patient's key problems. Nevertheless, these types of instruments can be invaluable as a starting point in therapy.

\section{Instruments which elicit symptoms}

As psychotic patients present with multiple and complex problems, a thorough assessment of a range of potential problem areas in addition to the key psychotic symptoms is often helpful when first getting to know the patient. Eliciting information on non-psychotic symptoms is important as these may interact with, and impact on, the occurrence of the psychotic symptoms. This can help clinicians and patients to prioritise problems and to ensure that CBT is being applied to other psychotic symptoms appropriately. Instruments such as the Present State Examination (PSE; Wing et al, 1974) can be used to elicit symptoms and rating scales such as the Positive and Negative Syndrome Schedule (PANSS; Kay et al, 1989) can be used to rate the severity of the symptoms. This can provide a starting point around which a further analysis of the individual experiences can be assessed.

2. Instruments which measure the severity of the dimensions of psychotic symptoms 
Despite the above scales being invaluable as tools to assist clinicians in the early stages of engagement, they are not sufficiently specific to tell us anything about the nature of the individual dimensions of symptoms and how they co-vary as a result of treatment. This is necessary in cognitive-behavioural treatment to provide information to assist with generating the formulation, but also as a tool for monitoring outcome in therapy. For example, a patient who experiences a reduction in the distress caused by their hallucinations as a result of treatment may not show a concurrent change in their frequency or duration, therefore the improvement will not be picked up on measures of severity such as the BPRS. This is essential in CBT where treatment might be directed towards reducing the distress or other dimensions associated with a particular symptom rather than at removing or reducing the occurrence or frequency of a symptom. For some people, feeling more positive about the future or being in control of their symptoms is viewed as a good outcome from therapy and complete removal of the symptom may not be their priority. Scales are available which have been developed to measure the severity of a number of different dimensions of auditory hallucinations and delusions (Psychotic Symptom Rating Scales; PSYRATS; Haddock et al, 1999). Thirteen dimensions of auditory hallucinations (frequency, duration, amount of distress, intensity of distress, location, conviction of beliefs regarding origin, disruption, controllability, loudness, amount of negative content, degree of negative content, number, form) and six dimensions of delusions (amount of preoccupation, duration of preoccupation, amount of distress, intensity of distress, conviction, disruption) are elicited and rated by an interviewer on a five point scale which has specified anchor points. This type of instrument can be used at the beginning, during and following treatment to track changes in dimensions over time and to assess specific changes in individual dimensions.

3. Instruments for carrying out a cognitive-behavioural analysis of symptoms 
Instruments as described above are essential to allow us to monitor changes in symptoms over time but they are not sufficient to help a therapist to gain a detailed understanding of the variables which are contributing to the occurrence and maintenance of a symptom. This is essential to achieve a working formulation which will direct a psychological intervention. Structured interviews such as the Maudsley Assessment of Delusions Schedule (MADS; Buchanan et al, 1997) and the Antecedent and Coping Interview (ACl; Tarrier, 1994) are designed to achieve this. For example the MADS is a structured interview which is designed to elicit information from the patient about their delusions in terms of a large number of different variables e.g. the degree of conviction, the behaviours associated with the belief, the evidence which the patient holds which contributes to their conviction etc. The $\mathrm{ACl}$ is a structured interview which is designed to elicit the behavioural and cognitive antecedents and consequences associated with a symptom. For example, a patients' delusional belief may be maintained by the types of behaviour which the patient engages in. A paranoid patient may engage in continual searching for evidence which will confirm his belief that the whole world is against him and ignore disconfirmatory evidence. A detailed analysis of this is essential to provide the basis for intervention, which might involve helping the patient to change their interpretation of behavioural evidence.

The above structure can contribute to an overall assessment with a patient, but this also must be carried out in the context of a general assessment of other important need areas. Most patients who have a psychotic illness have multiple needs and it is important to fully assess all areas before intervening with psychotic symptoms. For example, many patients with psychotic symptoms are depressed or anxious (Tarrier, 1987) or are suicidal (Falloon and Talbot, 1981) and these nonpsychotic symptoms must be taken into account as removal of psychotic symptoms (especially if they are of a grandiose nature) may be detrimental for a patient if the 
removal results in a further increase in depression or anxiety. Likewise, some patients have symptoms which form an important part of their life e.g. supportive or comforting voices, for which removal of their symptoms may have a negative impact. This does not mean to say that this person cannot be helped to improve their functioning, but that the focus for intervention may be to improve that person's access to other support before intervening directly with the symptoms (Yusupoff and Haddock, 1997).

More detailed ratings scales and monitoring tools can be used to explore hypotheses generated by a formulation. For example, it is possible that early assessment may reveal that one person's voices appear to be associated with certain types of interactions or events. It may be useful to get the patient to concurrently monitor these types of situations by recording the antecedent and consequential events surrounding a symptom occurring in terms of behavioural, physiological and cognitive factors. This may help the therapist and patient gain a clear idea of the types of thoughts and emotions which are contributing to symptoms occurrence or worsening and provide an ideal place for intervention. These types of ratings or diaries can be kept by the patient and be made as simple or as complex as appropriate. They may also be an essential part of a treatment intervention e.g. a patient who expresses paranoid beliefs may utilise this type of monitoring tool to keep a record of the types of evidence collected during times when the belief is held most strongly. This may help the patient to keep a more objective record of the evidence which is used in support of their belief and this may then be reviewed during therapy sessions.

Monitoring tools may also play an important part of intervention with patients experiencing auditory hallucinations, for example, it has been noted that concurrent monitoring of these types of symptoms may reduce their severity (Haddock et al, 1993). In addition, focusing on the nature of auditory hallucinations may reduce the 
distress associated with them (i.e. serve a desensitisation purpose for some patients) and help some patients to explore the content, their respondent thoughts and feelings as well as explore the patients underlying beliefs which can add to the distress associated with voices (Chadwick and Birchwood, 1994). Strategies which can aid this type of focusing approach have been described in detail by Haddock and colleagues (Bentall et al, 1994; Haddock et al, 1996). The approach is designed to help patients to concurrently monitor their voices by gradually exposing themselves to increasingly emotive aspects of them. Monitoring begins by asking the patient to concurrently monitor only the physical characteristics of their voices. When the patient feels comfortable with this they can then move on to monitoring the content, their resultant thoughts and to focus on the beliefs which are activated as a result of the voices. Verbal and written shadowing (immediately repeating the content out loud or writing the content down) can aid focusing on voice content and thoughts and help the patient to discuss their voices without becoming aroused or distressed.

Assessment is an essential part of treatment for people experiencing psychotic symptoms, and as outlined above this can form an important part of treatment in itself. As a result of this, initial assessment may take a number of sessions and some assessment will be ongoing throughout the intervention. Once assessment material is collected, intervention can be informed by a working formulation of the patient's difficulties. This formulation will guide the intervention and help therapist and patient to decide on the priorities for treatment.

Initial stages of formulation

There are a number of underlying assumptions which should be borne in mind when attempting to formulate an individual's key problems. These apply in psychosis as much as in other disorders. 1. A persons mood/symptoms/problems are affected by his or her cognitions and beliefs 2 . Those cognitions and beliefs are 
modifiable, and 3. Modifying cognitions and beliefs will result in modified symptoms. These assumptions should underpin all of the assessment work which leads towards a preliminary formulation to be shared between therapist and client.

\section{Formulation}

An accurate and concise description of the main symptoms or problems should be made in terms of the presenting symptoms, the related key cognitions, affect, behaviour and specific and general beliefs. This should highlight how the individual's thoughts, feelings and behaviours may have interacted to contribute to the maintenance and development of symptoms or problems and how these may be targeted using CBT to alleviate the individual's distress. This formulation is used to guide the direction and content of therapy. If possible, this should be generated collaboratively as a summary and reflection of the information that has been elicited and collected during assessment. The impact of presenting the formulation and the complexity required should be considered in advance and should take account of the individual's needs and cognitive ability. For some people, a simple summary of their main problems areas is sufficient. For others, a more complex model can be presented. It is often easier to add to the formulation later rather than present something complex initially. The formulation should be prepared in a way that is easily understandable and can be prepared in a written as well as a verbal form. Written material is useful to allow both therapist and individual to have a record of what has been discussed in therapy. It also encourages feedback and potential for modification. Audio recordings of sessions are also useful and can be used by therapists and individuals to listen to between sessions and/or to keep as a record of the session.

The formulation should be refined and modified, in negotiation with the patient and in the light of evidence. This may be an ongoing process throughout therapy. For some people, the initial part of the intervention process may relate to 
helping them to generate evidence which supports the formulation. This can serve to highlight how cognitions are affecting behaviour and mood and to help them to pinpoint how particular interventions might be useful. For example, an individual may agree that the formulation reflects certain aspects of their difficulties but believe that it does not account for some occurrences of the problem or that there are parts of the formulation which do not quite fit. The therapist and client can then generate homework tasks designed to test out the formulation in the light of events which occur between sessions. This process helps the client to fine-tune the formulation and to increase their motivation for change.

Intervention strategies based on the formulation

Using the information recorded in the formulation, appropriate targets or goals should be prioritised for intervention collaboratively. These should usually be explicit although it is possible that there may be instances when the therapist may have different or additional goals from the client. The potential outcome of implementing a particular intervention or strategy should be assessed in terms of positive and negative consequences with reference to the formulation. The interventions should be selected in terms of the degree of expected effectiveness with respect to the particular problem area targeted, but should also take into account client's motivation, ability and the achievability of the goal. In addition, safety and risk factors should be considered at all times in relation to any intervention.

In the absence of life threatening difficulties, the initial goals are likely to be focused on symptom reduction or the modification of coping strategies. Underlying core and long standing beliefs and behaviour patterns influencing current problems may to be tackled at a later stage in therapy, if appropriate, though there are instances when interventions might be concurrently targeted upon these areas. Interventions 
Interventions should be directly related to addressing goals which are pin-pointed in the formulation and are likely to cover the following areas: delusions, hallucinations, anxiety, depression, suicide, relapse prevention/keeping well, schemas, coping strategies, negative symptoms, medication compliance. However, this list in not exhaustive and interventions may vary considerably from individual to individual.

Commonly used cognitive-behavioural intervention techniques include: ongoing monitoring of key cognitions, behaviours and feelings, strategies to test out delusional or core beliefs (e.g. behavioural experiments), strategies to challenge and modify negative thoughts, strategies to enhance coping, developing helpful distraction strategies, motivational work to increase desire to take helpful medication. These approaches will be used collaboratively and will aim to reduce the distress and disruption of the individual's symptoms. They may not result in removal of the symptoms although for some people this is an outcome from therapy.

Figure 1 illustrates an example of a formulation of an individual (James) whose main problem relates to hearing derogatory and abusive voices.

\section{Figure 1 about here}

This formulation highlights how recurrent conflict with his partner increases James's arousal levels and results in intense physical anxiety symptoms and worries which have themes of 'inadequacy', 'hopelessness' and 'fear of being abandoned'. These thoughts tend to trigger an exacerbation of voice hearing which he believes are external spirits that are helping him. The 'spirits' endorse 
and confirm the accuracy of his negative thoughts and encourage him to 'give up on life by taking an overdose'. In the past he had taken an overdose to try to escape from his distress. He is often tempted to do this again as he believes it is his only way out of his torment but is stopped by his strong religious beliefs that taking of his life is a mortal sin. His most common way of dealing with his anxieties and voices is to drink. This blocks out his worries temporarily but ultimately results in more conflict with his partner and failure to address and challenge his beliefs about his inadequacy, hope and being abandoned. The formulation highlights how his thinking and behaviour contribute to his ongoing problems and suggests that changes in some of these areas may reduce the distress and disruption caused by his voices. For example, James became aware that his alcohol use was not being helpful and that it was actually contributing to a worsening of his situation by reinforcing both his and his partner's views that he couldn't cope or that he was inadequate. In addition, he was able to notice that his thoughts about himself were very negative and that there may be some virtue in challenging and assessing how accurately these reflected his true self. This also led to the realisation that the voices were 'extensions of his own thinking' and that by changing the way he thought about himself, that this could reduce the strength and impact of the voice content i.e. if he didn't agree with what the voices were saying, he wasn't so bothered about them being there. Generalisation, staying well and relapse prevention A key part of a psychological intervention is to ensure that the approaches worked on in therapy generalise beyond the end of therapy and to ensure that 
techniques and strategies used with the therapist can be used by the individual on their own. This can be facilitated by therapist and client developing a keeping well strategy during or at the end of therapy. The aims of this are to help the individual

1. Keep as well as possible and to continue to implement helpful strategies

2. To monitor and detect when things might not be going so well

3. To have an action plan that enables the individual to implement strategies to overcome difficult times or situations.

There are a number of ways that this can be achieved. The following example provides a guide to how this can be achieved for an individual.

\section{Example 1: A guide to staying well}

It can be helpful to put together a keeping well plan with your therapist. This may help you to maintain the gains you have made in therapy and help you to keep well in the future. A good place to start is by asking yourself the following questions. You may also want to discuss this with your therapist. Each person is different and individual so not all of the suggestions will apply to you. It's possible that none of them suit you, so please add your own personal suggestions so that you can create your own Keeping Well Manual.

\section{What things have helped me to feel better and overcome my problems?} (e.g. relationships, talking over my problems, changing my drinking or 
eating habits, managing my negative thoughts, challenging my paranoia etc)

2. What things should I avoid because they are not helpful or make things worse? (e.g. stressful situations, particular people, using drugs etc)

Once you have good idea of the things that are helpful/should be avoided, you can start to build up a plan to ensure that you have plans or strategies in place to deal with any future problems. Some people find it useful to put together a folder with useful tips and information that has been discussed in therapy. Some people might file things under the following headings.

The things that keep me well

How to I keep a check that things are going OK?

How do I know when things are starting to deteriorate and what shall I do if I notice this?

What to do if things get really bad?

Some people use a personal 'traffic light' system to help them to see easily how things need to be/what they should be doing when they are well (green), how they are when things are not so good (amber) and how they are when things 
have got really bad (red). The following shows an example of this (Figure 2). This way of doing it won't suit everyone, you might want to come up with other strategies or you might find that just going through the above is sufficient.

Figure 2 about here

Ensuring treatment addresses the phase of illness and the individual's developmental needs

The nature of a psychotic illness for many people is that it is long lasting and pervades all areas of an individual's life. The way it influences an individual may be very dependent on the developmental stage of the individual. For example, the therapeutic needs of an adolescent experiencing a first episode of psychosis may be very different from that of an older adult who has experienced treatment resistant symptoms for many years. A number of treatment programmes have been developed to meet the needs of the early psychosis group indicating that it is possible and beneficial to engage young people at very early stages of illness. Indeed, some programmes have focused on engaging those people who are displaying at risk signs of developing psychosis but who have not yet gone on to develop full-blown psychosis. For example, Morrison et al (2004) carried out CBT with a sample of 'at risk' individuals and demonstrated that this could reduce the conversion rate to full blown psychosis compared to a control group. Specific 
issues that may be particularly pertinent may be developmental issues, familial issues, issues in relation to the change from school to university or work and use of alcohol and cannabis.

Evaluations of the effectiveness of individual CBT

Individual CBT has been subject to much evaluation in controlled and uncontrolled trials. Several trials have demonstrated the superiority of CBT over control treatments and treatment as usual (usually anti-psychotic medication and care/case management approaches (See Pfammatter et al, 2006; Jones et al, 2007; Wykes et al, 2008 for reviews). Several meta analyses (Jones et al, 2007; Pfammatter et al, 2006; Rector and Beck, 2004) have come to slightly different conclusions, probably as a result of using different inclusion criteria for studies reviewed in the meta-analysis. Wykes et al (2008) in a recent meta-analysis concluded that CBT consistently showed superiority over control treatments, with an overall mean weighted effect size taken from 33 studies of 0.4 . However, the effect size of the treatment reduced in proportion to the quality of the methodology employed by the researchers carrying out the studies.

\section{Family interventions for psychosis}

A substantial amount of research has demonstrated that providing family interventions can significantly reduce relapse rates of people with psychosis over follow-up periods (Pfammatter et al, 2006; Pharaoh et al, 2006). Family interventions are based on the assumption that a stressful interpersonal environment in which an individual lives can exacerbate psychotic symptoms and 
lead to premature or more frequent relapse of illness. This type of stressful environment is often one referred to has being high in 'Expressed Emotion'. This term was first described in relation to families by Brown and colleagues (Brown et al, 1962) following observations that people with schizophrenia who were discharged from hospital to live with parents or close family fared worse than those who lived alone or in hostel accommodation (Brown et al, 1958). Brown and colleagues developed a measure of 'expressed emotion' (EE) that could be used to assess the emotional climate in an individual's home environment. It is characterised as one in which the interpersonal environment is high in critical comments, hostility and emotional over involvement. Research showed that those individuals living in environments scoring high on a measure of high EE resulted in significantly higher relapse rates for the individual with schizophrenia than those in low EE environments (Brown et al, 1962, Vaughn and Leff, 1976). This finding has now been replicated many times in different settings and in different populations. This type of environment is not thought to be a result of relatives or carers deliberately critical or hostile towards their relative. On the contrary, this behaviour is generally considered to be a result of a normal reaction to the incredible stress associated with experiencing a relative who has a psychotic illness. For example, it has been shown that relatives who demonstrate high levels of criticism for their relative's behaviour often believe that by doing so, they are assisting their relative to get back to their normal premorbid level of functioning (Barrowclough and Hooley, 2003). Those relatives who display high levels of emotional over involvement have been shown to hold 
beliefs that their relative's require a high degree of assistance and help to function and that they need to provide this, often at the expense of their own psychosocial functioning.

Family intervention treatment programmes

A number of different family approaches have been evaluated (see Pharoah et al, 2006 for review) and although they may differ in the techniques employed they tend to be cognitive-behavioural in their underpinning therapeutic model and have major aspects in common. They usually focus on attempting to improve the interpersonal environment by providing the following key elements: 1) assessment and problem formulation (as with CBT above) in order to identify key problem areas of individual and their relative 2) information about the nature of the illness, its prognosis and treatment and 3) intervention and problem solving strategies to address areas of conflict and concern, goal setting to improve social and interpersonal functioning of all family members.

Family interventions can involve close family members and carers and may also be effective with staff groups for people living in inpatient environments (Oliver and Kuipers, 1996). Interventions are often delivered with single families although interventions delivered to groups of families simultaneously have also been shown to be effective (McFarlane et al, 1995). There is no limit to the numbers of family members that can be engaged in the approach although for practical reasons it is often limited to those living in closest contact with the individual such as parents, partners, brothers and sisters. Family interventions typically last for between six and twelve months, with sessions weekly or 
fortnightly. The meetings are flexible with some sessions taking place as a family group with the individual, some taking place with relatives alone and others with the individual sufferer themselves. The exact nature of the sessions will depend on what is collaboratively agreed between all parties during the earlier assessment and formulation sessions. As the approach is collaborative, agreement from all parties as to what takes place is important within the confines of each stage. Further details of these stages are outlined below. However, as many of the principles of family intervention are similar to those required for individual CBT, a detailed description of the characteristics and principles of treatment will not be repeated here.

\section{Assessment of key problems}

As each family needs and problems will be unique to their situation, careful assessment about the nature of these is essential before proceeding to intervene. This may involve meeting with key relatives separately to gain the perspective on their situation, view of their relative's problems and their own mental health. Structured interviews and questionnaires can be used to assist with this process, for example, The Relative's Assessment Interview and Knowledge about Schizophrenia Interview (Barrowclough and Tarrier, 1992) and General Health Questionnaire (Goldberg, 1988).

2. Information about the nature of the illness, its prognosis and treatment Helping relatives and sufferers to gain correct information and understanding about the nature of the psychotic illness, the causes, prognosis and the treatment is often very important and can help correct erroneous beliefs that may have 
been driving relative's behaviour and can help with the discovery and implementation of more helpful behaviours. It can also reduce the distress and allay any fears that have arisen from erroneous mythical or media sources. It is helpful if information provision is delivered in a way that is 'tailored' to the needs of the family members. For example, some people will hold erroneous beliefs about cause of their relative's illness that is making them behave in a way that is not helpful. Believing that their relative's illness is a disability that results in the individual not being able to care for themselves could result in a concerned carer trying hard to provide as much support for their relative as possible. Whilst this is driven by good intentions, this may be at the expense of their needs or mental health and may actually be unhelpful for their relative as well. It can be useful to specifically target these types of erroneous beliefs when providing information in order that the relative can target their caring efforts more effectively. Careful assessment of the family's knowledge preceding offering information may be useful. Instruments such as the Knowledge About Schizophrenia Interview (Barrowclough and Tarrier, 1992) is a structured interview that is designed to elicit relative's knowledge about the nature of the illness, its cause, course, prognosis and treatment and can be useful for clinicians to use as a starting point for producing a 'tailor made' education package.

3. Intervention strategies to address areas of conflict and concern, set individual and family goals and improve functioning Specific intervention strategies will depend on the needs of the individual patient and their family, however, some common elements are usually involved. For 
example, most interventions will provide strategies to assist patients and carers to set realistic and achievable goals and provide assistance in achieving these with the intention of improving functioning of family members and patients. Some approaches will include strategies to assist with managing unpleasant affect, distress and symptoms. Action plans involving all family members are often used to assist relatives to monitor and detect early signs of relapse and to provide a plan of action should any family member become aware of early signs of relapse. The family intervention may also be delivered in tandem with individual cognitive behaviour therapy for family members and patients where necessary to deal with any individual problems (see Barrowclough and Tarrier, 1992; Falloon, 1985; Mueser \& Glynn,1995’ Kuipers, Leff and Lam, 2002 for detailed descriptions of interventions)

\section{Effectiveness of family interventions}

Family interventions have been rigorously evaluated indicating consistent superiority of the approach compared to treatment as usual on relapse rates (Pfammatter et al, 2006) with replications in many parts of the world including Eastern and developing countries (Xiong et al, 1994). Recent meta-analyses have varied in their conclusions however, reviews consistently conclude that family interventions can significantly reduce relapse. The recently updated Cochrane systematic review of family interventions in schizophrenia (Pharoah et al, 2006) concluded that family interventions can reduce the frequency of relapse, reduce hospital admission and increase adherence to medication. 


\section{Therapy at the neuropsychological level}

In addition to the developments in therapy for people with schizophrenia in individual CBT and family intervention, there have been parallel developments in the neuropsychological domain. Beginning in the 1970's, a set of techniques and supporting principles has evolved that extends the cognitive behavioural armamentarium for schizophrenia to the neuropsychological level. Not coincidentally, this paralleled the emergence of the hypothesis that schizophrenia is, among other things, a neurocognitive disorder (e.g. Green, 1998). It is increasingly clear that neurocognitive impairment plays an important role in vulnerability to schizophrenia (e.g. Walker, 1994) and in its course and outcome (e.g. Green, 1996). Neurocognitive impairment compromises social functioning and response to rehabilitation in the short term (Penn et al, 1992, 1993; 1995,1996; Bowen et al, 1994) and global recovery in the long term (Green, 1996). The effectiveness of antipsychotic drugs in treating neurocognitive impairment has been generally disappointing. These findings stimulate the hypothesis that psychological approaches to reducing or eliminating neurocognitive impairments might be helpful.

Clinical procedures for assessment and treatment of neurocognitive impairment draw heavily from work in the clinical neuropsychology and experimental psychopathology of psychotic disorders. They are also heavily influenced by familiar principles of CBT as described above. These include the need to quantify and monitor the target of treatment, the need for well defined and manualized procedures, the need for outcome criteria that reflect significant 
behavioral dimensions of personal and social functioning, and the importance of scientific support for clinical effectiveness.

Definition of the approach

There is no universally accepted title for this set of techniques and related research. The term cognitive remediation often appears in the literature, but is met with the objection that there is no evidence that something gets "remediated" in the course of treatment. Cognitive therapy avoids the connotation of a hypothetical treatment mechanism, but does not distinguish from the familiar schematic therapy model described above. Neuropsychological therapy is more descriptive, but not widely used, perhaps because of potentially misleading connotations of "neuropsychological." Neurocognitive therapy avoids the connotations of "neuropsychological," but does not fully describe the principles involved or the range of techniques. "Rehabilitation" appears interchangeably with "therapy." Arguably, CBT for neuropsychological functioning best describes most of the techniques, but many are very different from conventional CBT.

Terminology aside, the primary principle common to all members of the set is that personal and social functioning can be improved by strengthening impaired cognitive processes that normally support that functioning. This is distinct from the CBT principle underpinning the approaches described in the earlier section above, i.e. that behaviour change is facilitated by changes in cognition. CBT mostly involves manipulation of declarative and procedural information structures, such as beliefs, attributions and self-regulation skills. The processes that support or operate upon those structures (perception, attention, 
memory, etc.) are usually assumed to be more-or-less intact (although CBT does include some manipulation of processes as well as content, and in this sense the two approaches overlap somewhat). In CBT for neuropsychological functioning those processes are known or assumed to be impaired and are therefore the targets of treatment. For the purposes of this chapter, the rhetorically economical and reasonably descriptive term neuropsychological therapy (NPT) will be used to describe the approach.

Neuropsychological therapy (NPT): a description of the approach In practice, NPT consists of therapeutic exercises in which the patient performs tasks that require use of the cognitive processes being treated. The tasks are generally derived from neuropsychological and psychopathological tests that measure those processes. The cognitive constructs reflected in these tasks fall mostly under the categories of attention and executive functioning, e.g. vigilance for signal events, continuous performance of simple motor behaviors, resistance to distraction, concept formation, working memory, problem solving. The tasks are performed in a range of formats, ranging from dyadic therapy (comparable to the dyadic format in conventional CBT) to group therapy (also comparable to CBT group formats) to occupational/vocational formats (such as used in day programs and therapeutic industrial workshops). The treatment protocol is usually designed to first establish normal performance with simple versions of a task, and then gradually add complications to approximate performance demands in more real-life circumstances. Accordingly, the key outcome measures shift as treatment proceeds, from performance on laboratory tasks or 
in group therapy exercises to performance of meaningful activities in natural environments. In comprehensive psychiatric rehabilitation programs, there is a natural segue from NPT to social skills training and related modalities (discussed in the next section).

Many NPT exercises have been computerized. These generally resemble comparable tasks developed for rehabilitation following traumatic brain injury, and in fact the latter are often used in cognitive remediation for schizophrenia and related disorders.

The therapist's role in NPT is generally to introduce and explain the tasks, and in some cases provide various kinds of assistance. Assistance ranges from simple social reinforcement (encouragement) to prompting specific behaviours (e.g. "pay attention to the screen") to more complex coaching protocols. Coaching often includes prompting "self-talk" comparable to self-talk techniques of conventional CBT (e.g. Meichenbaum, 1969; Meichenbaum \& Cameron, 1973). Coaching may also include procedures intended to help the patient develop a meta-cognitive perspective on the task, i.e. analyzing the cognitive abilities and strategies required for task performance, and then using that information to self-prompt acquisition and/or activation of those abilities and strategies. Also as in conventional self-talk approaches, the therapist prompts self-reinforcement, and as in modern CBT, reinforces the patient's sense of mastery and consequent benefits to self-esteem. The therapist also monitors and evaluates progress. Depending on the particular approach and on individual 
patient needs, the therapist makes ongoing decisions about adjusting task difficulty or moving on to other exercises.

A few examples are described here to show the range of specific procedures included under the rubric of NPT:

A simple non-verbal vigilance exercise: the patient watches a computer screen showing changing geometric shapes of varying colors. When the colors of two of the figures match, the patient is to respond by pressing a button. This type of task can be made into a working memory exercise by adding more complex stimuli and response contingencies (e.g. "press the button when you see a square preceded by two triangles").

A group-format concept abstraction exercise: A group of patients are dealt special cards that include various combinations of shapes, numbers and colors. In turn, the group members identify different ways to organize and categorize the cards, and then physically sort them accordingly (neuropsychologists recognize this as an exercise version of the familiar Wisconsin Card Sorting Task).

An attention-focusing distraction resistance task: A patient listens for target words played over earphones to one ear while ignoring various kinds of audio distraction played to the other ear. 
An interpersonal verbal perception, concept abstraction and working memory task: The patient listens to declarative statements and brief narratives spoken by a group partner, then repeats, first verbatim and later for conceptual content.

A group-format concept formation/problem solving exercise: A group of patients engage in the familiar parlour game "20 questions" with coaching by the therapist that emphasizes use of logical, systematic questioning strategies instead of random guesses.

A social schematization exercise: A group of patients systematically analyze the stimulus features and then the thematic content of a picture of a complex social situation, while the therapist coaches toward complete and accurate perception and avoiding unwarranted inferences.

It is increasingly practical to implement NPT in real-world clinical settings. Manuals, training materials and program development consultation are available from a number of the research groups working in this area (Hogarty \& Flesher, 1999, Wykes \& Reeder, 2005; Brenner, et al, 1994; APA/CAPP Task Force, 2007). In some venues NPT is acknowledged and reimbursed as an evidencebased practice for people with chronic psychotic disorders, and this is expected to increase as the technology is further disseminated. 
There is a closely related but different approach, attention shaping (Silverstein, Menditto \& Stuve, 2000; Silverstien, Spaulding, Menditto, Savitz, Liberman, Berten \& Starobin, 2008). Attention shaping is an operant learning procedure, wherein patients in conventional psychoeducational or skill training groups are systematically reinforced with tokens, on a moment-to-moment basis, for engaging in the training process. In contrast to NPT, attention shaping does not rely on cognitive or neuropsychological constructs. The target behavior is behavioral attending (eye contact, attentive posture, etc.) and participation in the group activity. Attention shaping does share an important proximal outcome dimension with NPT, improved performance in psychoeducation, skill training and related rehabilitation modalities.

Another closely related approach, errorless learning (O'Carrol, Russell, Lawrie \& Johnstone, 1999; Kern, Liberman, Kopelowicz \& Mintz, 2002; Kern, Green, Mitchell, Kopelowicz, Mintz \& Liberman, 2005), uses learning principles to enhance acquisition of key skills. These skills include elemental abilities such as repeatedly performing work tasks (e.g. as needed in assembly line type work). However, as with attention shaping, the mechanism of the treatment effect is assumed to be the enhancement of normal learning, not enhancement of impaired cognitive processes.

\section{Outcome research methodology and evidence base}

Although a number of randomized controlled trials and two meta-analyses (Twamley, Jeste \& Bellack, 2003; Kurtz, Moberg, Gur \& Gur, 2001) support the effectiveness of NPT, its effectiveness is not beyond question. One meta- 
analysis (Pilling, Bebbington, Kuipers, Garety, Geddes, Martindale, Orbach \& Morgan, C. 2002) concluded there are no beneficial effects on ecologically important dimensions of personal or social functioning, although this analysis included a very limited number of original studies. The ambiguity in the findings stems partly from inconsistent and ambiguous definitions of NPT (or whatever else it might be called). The authors of one meta-analysis (Twamley et al, 2003) noted that the techniques they analyzed fell into at least four logically distinct categories. Similarly, outcome measures are diverse and have varying degrees of a priori ecological validity (the degree to which the measure has obvious relevance to real-life functioning). Nevertheless, combining all in a single analysis, they computed small to medium effect sizes. Considering the heterogeneity of the techniques and outcome measures, a small to medium effect size is quite promising, and probably a conservative estimate of effectiveness when tailored to individual patients with particular types or profiles of cognitive impairment, or to specific purposes.

Generally, the research evidence on cognitive remediation is strongest in demonstrating that people with schizophrenia and related disorders can improve performance on the particular abilities that are exercised in treatment. Although this has limited implications for overall recovery, it is a key research finding. Much skepticism toward NPT is based on the presumption that neuropsychological or neurocognitive impairments in schizophrenia are permanent and immutable. The research evidence also strongly supports effective enhancement of patients' response to other specific rehabilitation 
modalities, e.g. social skills training and occupational/vocational programs. There is insufficient evidence concerning highly generalized benefits, e.g. improved interpersonal functioning, self-esteem or quality of life. Unless such generalized benefits can be demonstrated independent of other treatments, cognitive remediation will likely become recognized as a useful, sometimes crucial component of more comprehensive psychiatric rehabilitation, rather than as a stand-alone treatment approach.

One unexpected methodological complication in NPT research is the possible relevance of nonspecific treatment effects. Most longitudinal studies of cognitive impairments in schizophrenia suggest they are remarkably stable over time, refractory to "treatment as usual" and persistent between episodes of relapse or exacerbation (e.g. Nuechterlein \& Dawson, 1984; Addington \& Addington, 1999). These were among the findings that spurred development of NPT in the first place. However, the control conditions in some trials of NPT have been unusually rich, including psychiatric rehabilitation modalities substantially beyond "treatment as usual." In at least one study that specifically analyzed cognitive changes in an enriched control condition (Spaulding et al, 1999) substantial improvements were observed (although not as great as in the treatment condition). It therefore appears that cognitive recovery may generally be more possible than previously believed, whether or not the treatment and rehabilitation regimen includes modalities that explicitly address cognitive impairments. Accordingly, research on cognitive remediation has shifted, from simply demonstrating overall benefits to analyzing the particular dimensions of 
treatment and rehabilitation that may enhance cognitive recovery in a variety of contexts (for a more extended discussion, see Silverstein \& Wilkness, 2004).

NPT research is thus moving in the direction foreseen by earlier behavior therapy researchers, toward articulating more precisely which therapy accomplishes what outcome for whom under what circumstances. The moderating factors for NPT effects are likely to include the severity and profile of neuropsychological impairment, the availability of comprehensive psychiatric rehabilitation and its nonspecific cognitive benefits, and the particular purposes to which NPT is applied. In some cases, the most important benefits may be highly generalized, broadly affecting many domains of personal and social functioning, while in others it may be specific to enhancing engagement in other key rehabilitation modalities.

\section{Theory base}

Considering the diversity and heterogeneity of neuropsychological and behavioral impairments in severe mental illness, it is unlikely that a single mechanism can account for all NPT treatment effects. The mechanisms that produce cognitive recovery with NPT may be the same, different or overlapping with those that produce nonspecific benefits in enriched rehabilitation milieus. Proposed explanatory mechanisms tend to fall within 5 (or so) categories (neither the categories nor the specific proposed mechanisms are mutually exclusive):

1. Enhanced normal learning: Psychiatric rehabilitation in general, and cognitive remediation in particular, facilitate acquisition of new or lost skills by overcoming barriers to learning created by cognitive impairments. Cognition itself is not 
changed or "remediated." New skills are acquired that would not be acquired without enhanced learning conditions. This is also the theoretical mechanism for attention shaping and errorless learning procedures. Enhanced normal learning could also account for nonspecific effects in treatment milieus that explicitly enrich learning conditions, such as in token economies and related contingency management approaches.

2. Learning compensatory cognitive skills: Cognitive impairments are not "remediated." The patient learns new cognitive skills, including non-verbal procedural skills that neither patient nor therapist can necessarily verbally articulate, that enhance task performance despite the remaining impairment (Kurtz, 2003). This mechanism is related to the enhanced normal learning mechanism above, and is similar to the "self-talk" mechanism historically proposed to account for some of the effects of conventional CBT. In self-talk explanations, individuals learn to verbally prompt themselves to activate key cognitive processes that would normally be automatically activated by eliciting circumstances. The self-prompts acquired in NPT may be non-verbal and procedural, as well as verbal self-talk.

3. Post-psychotic response repertoire reorganization: Acute psychosis disables a dopaminergic subcortical brain mechanism that normally adjusts the accessibility of elements of a person's response repertoire according to environmental demand (Spaulding, Sullivan \& Poland, 2003, chap. 6). Even after neurophysiological stabilization, environmental input is required to re-establish accessibility of key cognitive abilities, e.g. social perception and problem solving. 
Post-acute cognitive impairment is a residual inability to activate these abilities when needed. An enriched rehabilitation milieu encourages repertoire reorganization by providing high environmental structure, immediate and concrete response contingencies (e.g. via behavioral contingency programs) and much prompting for adaptive social behavior. Cognitive remediation provides an even more focused regimen for re-establishing the accessibility of key neuropsychological processes and abilities, especially those needed for interpersonal functioning and adaptive problem solving.

4. Enhancing automatization of cognitive processes: Human cognition normally involves execution of many processes that operate automatically without conscious or verbal monitoring. Skill acquisition is in large part automatization of specific abilities that would not otherwise operate automatically. Automatization is impaired in severe mental illness. NPT identifies key abilities that need to be automated to perform certain tasks and provides special conditions in which the automatization deficit is overcome. Versions of this explanatory model have been proposed by two groups, one in terms of basic, conventional neuropsychological processes (Wykes \& Reeder, 2005, chap. 8), the other in terms of automatic processing of complex social situations not conventionally addressed in neuropsychology (Hogarty \& Flesher, 1999).

5. Neuroendocrine activation: Chronic psychotic disorders compromise the diurnal activation cycle of the hypothalamic-pituitary-adrenal regulatory system. One hormone in the HPA system, cortisol, plays a key role in activating cortical neurons for cognitive processing. When the diurnal activating function of cortisol 
is compromised, the result is cortical hypoactivation and consequent cognitive impairment. A highly structured, enriched rehabilitation milieu provides stimulation sufficient to recover the diurnal activation cycle (Spaulding et al, 2003, chap. 6 ; note that this mechanism is probably more pertinent to nonspecific benefits of a rehabilitation milieu than specific effects of NPT).

In summary, NPT is promising as a component of comprehensive psychiatric rehabilitation. Its overall benefits have been demonstrated in controlled clinical trials. Further research is expected to identify key moderators of the treatment effect so that treatment can be more precisely tailored to individual needs. Similarly, further research will identify specific purposes, e.g. enhancing response to social or occupational skill training, for which NPT is most effective. A complete understanding of the mechanisms of the treatment effect will probably emerge gradually, as research is extended to increasingly particular populations and clinical circumstances.

\section{Social skills training and integrated approaches}

Social skills training (SST) is one of the oldest and most familiar behavioural therapy approaches applied to schizophrenia. It originated in the 1960's coincident with comparable behavioural approaches for other disorders. Its most complete and extensive development is in the work of Robert Liberman and colleagues at UCLA, who have been disseminating manuals and training materials for many years (Liberman, in press). There are numerous other accessible sources (e.g. Bellack, Mueser, Gingerich \& Agresta, 2004; Pratt \& 
Mueser, 2002; APA/CAPP Task Force, 2007), and a strong SST program can be developed in real-world settings with a modest amount of administrative and fiscal support. In the context of comprehensive psychiatric rehabilitation, SST is one component that can address specific problems and barriers to recovery. However, the principles of SST complement and extend broader principles of CBT and of psychiatric rehabilitation, and in that sense an SST perspective can pervade all aspects of services for people with severe mental illness.

Definition: SST is a structured procedure designed to strengthen the cognitive and behavioural elements that comprise interpersonal functioning. These elements include accurate perception and understanding of interpersonal situations, appropriate choice of behavioral response in specific situations, and competent performance of those behavioral responses. The initial objective of SST is to establish competent interpersonal behavior within the structured therapy situation. The longer-term objective is to generalize those competencies to the natural environment.

To varying degrees, SST approaches include interpersonal problem solving as an element of social competence. Interpersonal problem solving is a cognitive construct, in the sense that it can be characterized and taught in terms of specific analytical steps: 1) recognize there is a problem or conflict 2) articulate the nature of the problem 3) generate a menu of possible behavioural responses or solutions 4) choose one solution and implement it and 5) evaluate the results. However, interpersonal problem solving cognition does not naturally 
occur in the way it is structured in SST, and in that sense it is more properly a heuristic model, not a true cognitive construct.

Description of the approach

The version of SST most common in settings that serve people with severe mental illness is a highly structured group modality. The therapist explains that the purpose of the group is to help people become more effective in their social and interpersonal interactions and relationships. In early phases of treatment, there are brief didactic presentations on specific kinds of interactions, e.g. how to strike up a casual conversation, how to make a request, how to express pleasure or displeasure. This is followed by role playing, in which designated members play parts in contrived social situations. During the role playing, the other group members function as observers. The therapist directs the role play, setting up the situation, sometimes prompting the players, and ending it at an appropriate point. After the role play, the therapist gives feedback to the players, couched as praise and constructive criticism. Further feedback is prompted from the other group members, who follow the same protocol of first praising the strengths of the role play and then suggesting alternatives for suboptimal responses. The role play is repeated as the players incorporate the feedback and hone the effectiveness of their behaviour.

Role plays of simple situations are followed by more complex ones, as skills develop. In later phases, patients are asked to bring their own personal experiences to the group for role playing. When the role play portrays a particular problem or conflict in a patient's life, the patient is prompted to try out the role 
played solution in the real world and report back to the group on its effectiveness. In some SST versions, an interpersonal problem solving model is introduced after the initial phase, and the group members practice applying this model to conflicts and problems they encounter. Some versions of SST are time-limited, identifying specific behavioural competencies as the treatment goal and the criterion for discontinuation. SST is also often used as an open-ended continuing modality, comparable to long-term supportive group therapy but with continuing use of specific role-playing and problem solving exercises.

\section{Outcome research methodology and evidence base}

The effectiveness of SST has been demonstrated in many clinical trials, but meta-analyses yield inconsistent results. Three meta-analyses of SST studies (Benton \& Schroeder, 1990; Corrigan, 1991; Dilk \& Bond, 1996) found strong evidence for effectiveness in improving social competence, suppressing symptoms and postponing relapse. A fourth (Pilling, Bebbington et al, 2002) found no evidence for any kind of effectiveness. A broader meta-analysis of SST and related psychosocial treatment (Pfammatter et al, 2006) found qualified evidence for effectiveness. A review of the problem solving component in SST (Xia \& Li, 2007) found insufficient studies to conduct a quantitative meta-analysis, and did not reach positive or negative conclusions. This confusing picture is at least partially attributable to the remarkable scope of application of SST and to the diversity of outcome criteria. Individual trials show strong benefits for a particular application with particular outcome measures, but questionable comparability of applications and outcome measures across trials undermines 
the effectiveness of quantitative meta-analyses. As with neuropsychological therapy, the strongest evidence is for effects on the particular abilities that are directly addressed in the group. The evidence becomes weaker for generalization of these effects to natural settings, and for generalization to domains of functioning beyond social competence.

Some key factors contribute to the popularity of SST despite the mixed evidence base. First, as Pilling, Bebbington et al (2002) pointed out, it has strong a priori validity. The relevance of competent interpersonal functioning to recovery from severe mental illness is obvious. Similarly, SST's emphasis on interpersonal functioning and its focus on problems actually encountered by patients are especially complementary to contemporary recovery-oriented perspectives on mental illness. Second, most patients like SST. They have the sense that it is addressing issues that are personally relevant and important. They often experience it as quite distinct from less helpful therapy experiences they have had. Third, the therapy skills involved in providing SST are easily generalized to other skill training applications, such as illness management, occupational and independent living skills (in fact, these are considered by some to simply be variants of SST). Investment in training a cohort of competent SST trainers can return benefits across an entire rehabilitation program. Integration with other modalities

The close historical relationship between SST and the broader psychiatric rehabilitation paradigm has encouraged integration of SST with other rehabilitation modalities. The first such integration was with the problem solving 
model, reflecting the more general integration of behavioural and cognitive approaches in the 1970's and 1980's. More recently, neuropsychological therapy (NPT) has been integrated with SST. At least two of the manualized NPT systems (Brenner et al, 1994; Hogarty \& Flesher, 1999) segue to procedures that are recognizably SST. Both NPT and SST can be applied in occupational/vocational contexts, further expanding opportunities for integration. In the future, as the active ingredients and optimal applications of NPT and SST are identified, it is likely that both approaches will lose their separate identities, becoming instead specific principles and techniques that can be applied in a variety of ways for a variety of purposes in the context of a broader, integrated rehabilitation and recovery enterprise.

In summary, SST is a structured, evidence-based treatment approach which can nevertheless be applied in a variety of rehabilitative skill training contexts. SST therapy principles and skills generalize to a range of contexts, and can even serve as a basis for dyadic therapy. The specific benefits of SST depend on the specific application, but improved interpersonal competence is an outcome that permeates most applications.

\section{Contingency Management}

Contingency management is a genre of techniques that evolved from learning and social-learning theories in the 1960s and treatment programmes based on the principles received particular attention during the 1970s in inpatient settings (see Corrigan \& Liberman, 1994). However, as community-based programs for 
people with severe mental illness have proliferated, the relevance of contingency management has not widely generalized, particularly in the UK. Nevertheless, contingency management is one of the most underutilized technologies in adult mental health services.

In contingency management approaches, a specific target behaviour is identified; whose increase or decrease would have therapeutic benefit for the individual. A precise, quantitative record, usually based on systematic staff observation, is kept of the occurrence of the behaviour of interest. Following a functional analysis of the environmental events which may prompt or reinforce the behaviour of interest, a plan or "programme" is developed wherein key people in the patient's social environment deliver or withhold reinforcers contingent on the occurrence or non-occurrence of the behaviour. The record is continually re-analyzed to determine whether the behaviour responds as desired to the alteration of environmental contingencies.

The earliest applications of contingency management for schizophrenia, in the form of token economies in psychiatric hospitals, provided some empirical evidence of effectiveness in promoting adaptive behaviour (Ayllon \& Azrin, 1965; Baker et al, 1977). In a 7 year controlled clinical outcome trial (Paul \& Lentz, 1977), described at the time as "the largest outcome trial in the history of psychiatry," a rehabilitation program that included contingency management was vastly superior to psychiatric treatment as usual. However, there have been relatively few controlled trials of the approach (see McMonagle and Sultana 2000; Dickerson et al, 2005 for reviews of token economy in schizophrenia) 
although, clinical evaluations, case studies and institutional experience continue to support its effectiveness in suppressing or changing behaviour and symptoms (particularly negative symptoms), increasing adaptive behaviour and increasing participation in treatment and rehabilitation (e.g., McMonagle et al, 2000; Paul \& Menditto, 1992; Wong, Massel, Mosk, \& Liberman, 1986). In addition to general effects on maladaptive and adaptive behaviour, when combined with other social-learning modalities, contingency management has been shown to be effective with two of the most troublesome and drug-resistant problems encountered in inpatient settings, aggression (Beck et al., 1997; Beck, Menditto, Baldwin, Angelone, et al, 1991) and polydipsia (Baldwin, Beck, Menditto, Arms, et al, 1992).

As many of the studies evaluating the approach are not recent, it is uncertain how approaches will perform with patients on contemporary inpatient units, in community settings or other types of residential programs. As a result, there is further need for trials evaluating its effectiveness in different settings. Also, it should be noted that contingency management is often used "informally," without a recognized need for professional supervision (any time a staff person says to a patient "if you do $X$, I will do $Y$ " it is a form of contingency management, whether therapeutically intended or not). As concern for patients' rights and demand for evidence-based treatments have increased, professionally supervised contingency management may need to be increasingly recognized as a key component in services for people with severe mental illness, especially in inpatient and institutional settings. 


\section{Co-morbid disorders}

Most of the application and evaluation of CBT for psychosis has been carried out with people without co-morbid disorders, however, perhaps due to the high proportion of people presenting to services with co-morbid disorders, greater attention has been paid to these groups in recent years. Areas where particular attention has been paid has been in people with co-morbid substance misuse disorders, those with co-existing problems with violence and aggression and those with learning difficulties.

Substance use

Co-morbid substance use in those people with a diagnosis of schizophrenia is higher than in the non-psychotic population and affects a significant number of sufferers. Estimates of prevalence vary depending on the location and type of participants included, however, the widely cited NIMH Epidemiological Catchment Area study (Regier et al, 1990) identified $47 \%$ of participants with a diagnosis of schizophrenia to have a lifetime prevalence of some form of substance use. The presence of substance misuse is associated with a range of negative outcomes, such as, higher rates of violent and aggressive behaviour, higher and more frequent relapse rates, higher suicide rates and poorer engagement and adherence with services (Maslin, 2003). The reasons for the inflated rates are not clearly elucidated; research suggests a number of contributory factors that vary amongst individuals, for example, to control 
unpleasant symptoms, manage side effects, to cope with unpleasant affect and to increase social confidence (Gregg et al, 2007).

Although, there have been few controlled trials evaluating the effectiveness of treatments for this sub-group of people, service evaluations and evidence from pilot trials suggests that strategies integrated to address both the problems of psychosis and substance use are necessary together with assertive approaches that optimise the engagement of individuals into treatment (Mueser and Drake, 2003). Integrated programmes have usually consisted of the following elements: 1) Motivational interviewing strategies (Miller and Rollnick, 2002) to enhance engagement, to identify personal and important individual goals and to explore and increase motivation to change substance using behaviour, and 2) Individual psychological therapy (usually CBT) to implement change in substance using and problems associated with psychosis. The rationale behind this is that the psychosis and substance use problems are not independent from each other hence should be addressed simultaneously. Where family members or carers are present, family interventions have also been viewed as important. Evaluations of this type of approach have shown significant benefits over treatment as usual (case management and anti-psychotic medication for mental health and substance use services) for a 9 month treatment with benefits at the end of the treatment period and at follow-up points (Barrowclough et al, 2001; Haddock et al, 2003).

Violence and aggression 
Violence and aggression, when associated with psychosis has tended to be associated with much media and public concern. However, the actual rate of violent crime associated with schizophrenia is low, attributed to about $5 \%$ of all cases of homicide and violent offences (UK National Homicide and Suicide Survey, Meehan et al, 2006). Nevertheless, within mental health services, aggression and violence are seen as significant areas of concern. The reasons for aggression and violence in psychosis are multifactorial and a number of key issues have been implicated. For example, the presence of particular types of delusional symptoms, such as threat control over-ride symptoms (delusions that contain content that is associated with perceived threat to the individual or belief that the individual's body or mind is being controlled by outside sources) have been associated with increased rates of violence in retrospective and prospective studies (Swanson et al, 1997, Link and Steuve, 1994) although findings have been inconsistent and other factors such as substance misuse, personality factors and affective states such as anger have also been implicated (Hodgkins, 2003; Appelbaum et al, 2000). Treatment programmes have been developed to address these issues. For example cognitive behavioural treatment programmes for anger delivered in a group format have been shown to significantly reduce the occurrence of violence and aggression at follow-up in forensic samples with psychosis (Renwick et al, 1997; Taylor et al, 2004). To date there has been little published work evaluating CBT in secure or forensic samples and little evaluation of their impact on violence and aggression outcomes despite this being an area of great concern for both the public and mental health services. However, a 
recent randomised controlled trial demonstrated that CBT can significantly reduce violence in people with psychosis who are at high risk for aggressive behaviour when the intervention is targeted simultaneously on psychotic symptoms and anger (Haddock et al, 2004, 2008) and when the intervention is preceded by motivational strategies to aid engagement. Further research in this area is warranted.

\section{Intellectual disabilities}

Although there has been very few controlled trials evaluating psychological treatments for people with psychosis and a co-existing learning disability, there has been some case series work and anecdotal material that suggests that the approaches can be adapted for this group with beneficial outcomes (Legget, 1997; Haddock et al, 2004). However some modifications are necessary, such as; less reliance on written sources of materials, and increased use of pictorial and symbolic means for communicating and particular attention to the cognitive abilities of the client. For example, concentration and understanding of material may be more limited. Shorter sessions, greater use of summaries, and repetition of material can be important. In addition, as CBT approaches rely to a certain extent on an individual's ability to make links between their problems, their cognition, emotion and behaviour, assessment of their ability to recognise the links between cognition, feelings and behaviour may be useful precursors to therapy to enable the intervention to be tailored to their abilities (Oathamshaw and Haddock, 2006). In addition, a preparatory phase for therapy can be 
included to enable some training in cognitive approaches to be carried out (Haddock et al, 2004; Taylor et al, 2004).

\section{Implementation and skills needed to deliver psychological therapists}

Whilst there is a large evidence base in support of psychological treatments for psychosis and substantial amounts of government guidance advocating their use, their implementation as routine interventions can be limited by the availability of trained therapists to deliver the treatments. The British Association of Behavioural and Cognitive Psychotherapies, European Association of Behavioural and Cognitive Therapies and the American Association of Behaviour Therapy all have minimum training standards and guidelines for the practice of CBT and there are specialist training courses providing clinicians with the necessary skills for applying the approach. Often these are designed to train mental health professionals who already have some of the skills necessary for engaging psychotic individuals in treatment (such as mental health nurses, clinical psychologists, psychiatrists) and provide training in the supervised practice of $\mathrm{CBT}$ over one to two years. The training involves face to face teaching in the theoretical and evidence base surrounding CBT and experience and practice of the approach with real clients with supervision from experts. Trainees are usually expected to demonstrate competence in the delivery of the CBT with clients in order to graduate and to continue to receive supervision when practicing. 


\section{Conclusions}

Psychological treatments are important in the treatment of psychosis and offer significant benefits in a range of areas, particularly, in reducing relapse, hospital admission, symptom severity and distress and improving cognitive functioning and performance. In addition, wider benefits for the individual and services may be observed, such as reduced violence and aggression, improvements in medication adherence, reductions in substance use, reduced suicide and benefits for relatives and carers. Further research is necessary to elucidate the exact ingredients for therapy and what treatment is best suited to which individual. 


\section{References}

Addington, J. and Addington, D. (1999) Neurocognitive and social functioning in schizophrenia. Schizophrenia Bulletin 25(1), p.173-182.

Alford, G.S. and Turner, S.M. (1976) Stimulus interference and conditioned inhibition of auditory hallucinations. Journal of Behaviour Therapy and Experimental Psychology, 7, p.155-160.

Allen, H.A., Halperin, J. and Friend, R. (1983) Removal and diversion tactics and the control of auditory hallucinations. Behaviour, Research and Therapy, 23, p.601-605.

APA/CAPP Task Force on Serious Mental Illness and Severe Emotional Disturbance (2007) Best practices for recovery and improved outcomes for people with serious mental illness. www.apa.org/practice/grid.html

Applebuam P.S., Robbins P.C. and Monahan J. (2000) Violence and delusions: data from the MacArthur Violence Risk Assessment Study. Archives of General Psychiatry, 157(4), p.566-72.

Ayllon, T. and Azrin, N.H. (1965) The measurement and reinforcement of behaviour of psychotics. Journal of the Experimental Analysis of Behaviour, 8, p.357-383.

Baker, R., Hall, J.N., Hutchinson, K and Bridge, G. (1977) Symptom changes in chronic schizophrenic patients on a token economy: a controlled experiment. The British Journal of Psychiatry, 131, p.381-393.

Baldwin, L., Beck, N., Menditto, A., Arms, T. and Cormier, J. (1992) Decreasing excessive water drinking by chronic mentally ill forensic patients. Hospital and Community Psychiatry, 43(5), p.507-509.

Barrowclough, C., Haddock, G., Tarrier, N., Lewis, S., Moring, J., Schofield, N., Quinn, J. and McGovern, J. (2001) Randomized controlled trial of motivational intervention, cognitive behaviour therapy, and family intervention for patients with co-morbid schizophrenia and substance use disorders. American Journal of Psychiatry, 158, p.1706-1713.

Barrowclough, C. and Hooley J. M. (2003) Attributions and expressed emotion: a review. Clinical Psychology Review, 23(6), p.849-880

Barrowclough. C. and Tarrier, N. (1992) Families of schizophrenic patients: a cognitive behavioural approach, London, Chapman and Hall. 
Beck, A.T. (1952) Successful outpatient psychotherapy of a chronic schizophrenic with a delusion based on borrowed guilt. Psychiatry, 15, p.305312.

Beck, N., Greenfield, S., Gotham, H., Menditto, A., Stuve, P. and Hemme, C. (1997) Risperidone in the management of violent, treatment-resistant schizophrenics hospitalized in a maximum security forensic facility. Journal of the American Academy of Psychiatry and the Law, 25(4), p.461-468.

Beck, N., Menditto, A., Baldwin, L., Angelone, E. and Maddox, M. (1991) Reduced frequency of aggressive behavior in forensic patients in a social learning program. Hospital and Community Psychiatry, 42(7), p.750-752.

Bellack, A., Mueser, K., Gingerich, S. and Agresta, J. (2004) Social skills training for schizophrenia: A step-by-step guide (2nd ed.), New York: Guilford Press.

Bentall, R.P., Kinderman, P. and Kaney, S. (1994) The self, attributional processes and abnormal beliefs: towards a model of persecutory delusions. Behaviour, Research and Therapy, 32(3), p.331-41.

Benton, M. and Schroeder, H. (1990) Social skills training with schizophrenics: A meta-analytic evaluation. Journal of Consulting and Clinical Psychology, 58(6), p.741-747.

Bleuler, E. (1911/1950) Demetia Praecox or the group of schizophrenias. New York, International University Press.

Brenner, H., Roder, V., Hodel, B., Kienzle, N., Reed, D. and Liberman, R. (1994) Integrated psychological therapy for schizophrenic patients. Toronto: Hogrefe \& Huber.

Brown, G. W., Monck, E. M., Carstairs, G. M., et al (1962) Influences of family life on the course of schizophrenic illness. British Journal of Preventive and Social Medicine, 16, p.55-68.

Buchanan, A. (1997) The investigation of acting on delusions as a tool for risk assessment in the mentally disordered. British Journal of Psychiatry, 170(suppl. 32), p.12-16.

Chadwick, P. and Birchwood, M. (1994) The omnipotence of voices. A cognitive approach to auditory hallucinations. British Journal of Psychiatry, 164(2), p.190201. 
Chadwick, P.D. and Lowe, C.F. (1990) Measurement and modification of delusional beliefs. Journal of Consulting and Clinical Psychology, 58(2), p.22532.

Corrigan, P. W. (1991) Social skills training in adult psychiatric populations: a meta-analysis. Journal of Behavior Therapy and Experimental Psychiatry, 22(3), p.203-210.

Corrigan, P. and Liberman, P. (Eds.) (1994) Behavior therapy in psychiatric hospitals, New York: Springer.

Dickerson, F.B., Tenhula, W. N. and Green-Paden, L.D. (2005) The token economy for schizophrenia: review of the literature and recommendations for future research. Schizophrenia Research, 75, issue 2.

Dilk, M. N. and Bond, G. R. (1996) Meta-analytic evaluation of skills training research for individuals with severe mental illness. Journal of Consulting and Clinical Psychology, 64(6), p.1337-1346.

Falloon, I.R. and Talbot, R.E. (1981) Persistent auditory hallucinations: coping mechanisms and implications for management. Psychological Medicine, 11(2), p.329-39.

Falloon I.R.H. (1985) Family management of schizophrenia, John Hopkins University Press, Baltimore

Garety, P.A. and Hemsley, D.R. (1997) Delusions: Investigations into the Psychology of Delusional Reasoning, Psychology press LTD.

Garety, P.A., Bebbington, P., Fowler, D., Freeman, D. and Kuipers, E.(2007) Implications for neurobiological research of cognitive models of psychosis: a theoretical paper. Psychological Medicine, 37(10), p.1377-91.

Goldberg D.P. and Williams, P. (1988) A user's guide to the General Health Questionnaire. NFER Nelson, Windsor.

Green, M. (1996) What are the functional consequences of neurocognitive deficits in schizophrenia? American Journal of Psychiatry, 153, p. 321-330.

Green, M. (1998) Schizophenia as a neurocognitive disorder. Boston, Ayllon \& Bacon.

Gregg, L., Barrowclough, C. and Haddock, G. (2007) Reasons for increased substance use in psychosis. Clinical Psychology Review, 27, p.494-510. 
Haddock, G., Bentall, R. P. and Slade, P. D. (1996) Focusing versus distraction approaches in the treatment of persistent auditory hallucinations. In Haddock, G. and Slade, P. D. (Eds.), Cognitive-behavioural interventions with psychotic disorders. London, Routledge.

Haddock, G., Barrowclough, C., Shaw, J.J., Dunn, G., Novaco, R.W. and Tarrier, N. (2008) Randomised controlled trial of cognitive behaviour therapy versus a social activity control treatment for people with psychosis and a history of violence. In submission.

Haddock, G., Lobban, F., Hatton, C. and Carson, R. (2004) Cognitive-behaviour therapy for people with psychosis and mild learning disability: a case series. Clinical Psychology and Psychotherapy, 11, p.282-298.

Haddock, G., Barrowclough, C., Tarrier, N., Moring, J., et al (2003) Randomised controlled trial of cognitive-behaviour therapy and motivational intervention for schizophrenia and substance use: 18 month, carer and economic outcomes. British Journal of Psychiatry, 183, p.418-426.

Haddock, G., McCarron, J., Tarrier, N. and Faragher, E.B. (1999) Scales to measure dimensions of hallucinations and delusions: the psychotic symptom rating scales (PSYRATS). Psychological Medicine, 29, p.879-889.

Haddock, G., Bentall, R.P. and Slade, P.D. (1993) Psychological treatment of auditory hallucinations: two case studies. Behavioural and Cognitive Psychotherapy, 21, p.335-346.

Haynes, S.N. and Geddy, P. (1973) Suppression of psychotic hallucinations through time-out. Behavior Therapy, 4, p.123-127.

Hodgkins, S, Hiscoke, U.L. and Freese,, R. (2003) The antecedents of aggressive behavior among men with schizophrenia: a prospective investigation of patients in community treatment. Behavioral Sciences and the Law, 21, p.521546.

Hogarty, G. E. and Flesher, S. (1999) Developmental theory for a cognitive enhancement therapy of schizophrenia. Schizophrenia Bulletin, 25(4), 677-692.

Hogarty, G. and Flesher, S. (1999) Practice principles of Cognitive Enhancement Therapy for schizophrenia. Schizophrenia Bulletin, 25(4), p.693-708.

Huxley, N.A., Rendall, M. and Sederer, L. (2000) Psychosocial treatments in schizophrenia: A review of the past 20 years. Journal of Nervous and Mental Disease, 188, p.187-201. 
James, D.A. (1983) The experimental treatment of two cases of auditory hallucinations. British Journal of Psychiatry. 143, p.515-6.

Jaspers, K. (1963) General Psychopathology (translated by J. Hoenig and M.W. Hamilton), Manchester, Manchester University Press.

Jones, C., Cormac, I., Silveira da Mota Neto J.I. and Campbell, C. (2007) Cognitive behaviour therapy for schizophrenia. Cochrane Database of Systematic Reviews 2007, Issue 4. Art. No.: CD000524. DOI: 10.1002/14651858.CD000524.pub2.

Kay, S.R., Opler, L.A. and Lindenmayer, J.P., (1989) The Positive and Negative Syndrome Scale (PANSS): rationale and standardisation. British Journal of Psychiatry, supplement. 7, p.59-67.

Kemp, R., Hayward, P., Applewhaite, G., Everitt, B. and David, A. (1996) Compliance therapy in psychotic patients: randomised controlled trial. British Medicine Journal. 10, 312, p.345-9.

Kern, R.S., Green, M. F., Mitchell, S., Kopelowicz, A., Mintz, J. and Liberman, R. P. (2005) Extensions of errorless learning for social problem-solving deficits in schizophrenia. American Journal of Psychiatry, 162(3), p.513-519.

Kern, R.S., Liberman, R. P., Kopelowicz, A., Mintz, J. and Green, M. F. (2002) Applications of errorless learning for improving work performance in persons with schizophrenia. American Journal of Psychiatry, 159(11), p.1921-1926.

Kuipers, E., Leff, J. and Lam, D. (2002) Family Work for Schizophrenia: A Practical Guide, second edition. London, Gaskill.

Kurtz, M.M. (2003) Neurocognitive rehabilitation for schizophrenia. Current Psychiatry Reports, 5(4), 303-310.

Kurtz, M.M., Moberg, P.J., Gur, R.C. and Gur, R.E. (2001) Approaches to cognitive remediation of neuropsychological deficits in schizophrenia: a review and meta-analysis. Neuropsychology Review, 11(4), p.197-210.

Legget, J., Hurn, C. and Goodman, W. (1997) Teaching psychological strategies for managing auditory hallucinations: A case report. British Journal of Learning Disabilities, 25, p.158-162.

Lewis, S., Tarrier, N., Haddock, G., Bentall, R.P., Kinderman, P., Kingdon, D., Siddle, R., Drake, R., Everitt, J., Leadley, K., Benn, A., Grazebrook, K., Haley, C., Akhtar, S., Davies, L., Palmer, S., Faragher, B. and Dunn, G. (2002)

Randomised controlled trial of cognitive-behavioural therapy in early 
schizophrenia: acute-phase outcomes. British Journal of Psychiatry, 181(suppl.4 3), p.91- 97.

Liberman, R. (in press) Recovery from disability: Manual of psychiatric rehabilitation. Arlington VA: Amercan Psychiatric Publishing.

Link, B.G. and Steuve, A. (1994) Psychotic symptoms and the violent/illegal behavior of mental patients compared to community controls. In J. Monahan and H.J. Steadman (eds.) Violence and Mental Disorders. Chicago, Chicago University Press.

Margo, A., Hemsley, DR. and Slade, P.D. (1981) The effects of varying auditory input on schizophrenic hallucinations. British Journal of Psychiatry, 139, p.122-7.

Maslin, J. (2003) Substance misuse in psychosis: contextual issues. In Graham, H.L. et al (Eds) Substance Misuse in Psychosis: Approaches to Treatment and Service Delivery. John Wiley \& Sons, Chichester.

McFarlane, W.R., Lukens, E., Link, B., Dushay, R., Deakins, S.A., Newmark, M., Dunne E.J., Horen, B. and Toran, J. (1995) Multiple-family groups and psychoeducation in the treatment of schizophrenia. Archives of General Psychiatry, 52, p.679-687

McMonagle, T. \& Sultana, A. Token economy for schizophrenia. Cochrane Database of Systematic Reviews 2000, Issue 3. Art. No.: CD001473. DOI: 10.1002/14651858.CD001473.

Meehan, J., Flynn, S., Hunt, I.M., Robinson, J., Bickley, H., Parsons, R., Amos, T., Kapur, N., Appleby, L. and Shaw, J. (2006) Perpetrators of homicide with schizophrenia: a national clinical survey in England and Wales. Psychiatric Services, 57, p.1648-1651.

Meichenbaum, D. (1969) The effects of instructions and reinforcement on thinking and language behavior of schizophrenics. Behavior Research and Therapy, 7, p.101-114.

Meichenbaum, D. M. and Cameron, R. (1973)Training schizophrenics to talk to themselves: A means of developing attentional controls. Behavior Therapy, 4, p.515-534.

Miller, W. and Rollnick, S. (2002) Motivational interviewing, New York, Guilford.

Morrison, AP; French, P; Walford, L; Lewis, SW; Kilcommons, A; Green, J;

Parker, S; Bentall, RP (2004) Cognitive therapy for the prevention of psychosis in people at ultra-high risk: randomised controlled trial. British Journal of Psychiatry, 185, p.291-297. 
Mueser, K.T. and Drake R.E. (2003) Integrated Dual Diagnosis Treatment in New Hampshire (USA) In Graham, $\mathrm{HL}$ et al (Eds) Substance Misuse in Psychosis: Approaches to Treatment and Service Delivery. John Wiley \& Sons, Chichester.

Mueser, K. and Glynn, S. (1995). Behavioral family therapy for psychiatric disorders. Boston: Allyn and Bacon.

Mueser, K.T. and Berenbaum, H. (1990) Psychodynamic treatment of schizophrenia: Is there a future. Psychological Medicine, 20, p.253-262.

Nelson, H., Thrasher, S. and Barnes, T.R.E. (1991) Practical ways of alleviating auditory hallucinations. British Medical Journal, 302, 307.

NICE guidelines for Schziophrenia (2007) Department of Health.

Nuechterlein, K. H. and Dawson, M. E. (1984) A heuristic vulnerability/stress model of schizophrenic episodes. Schizophrenia Bulletin 10, p.300-312.

Nydegger R.V. (1972) The elimination of hallucinatory and delusional behaviour by verbal conditioning and assertive training: a case study. Journal of Behaviour Therapy and Experimental Psychiatry, 3, p.225-227.

Oathamshaw, S. and Haddock, G. (2006) Do people with intellectual disabilities and psychosis have the cognitive skills required to undertake cognitive behavioural therapy? Journal of Applied Research in Intellectual Disabilities, 19, p.35-46.

O'Carroll, R. E., Russell, H. H., Lawrie, S. M. and Johnstone, E. C. (1999)

Errorless learning and the cognitive rehabilitation of memory-impaired schizophrenic patients. Psychology Medicine, 29(1), p.105-112.

Oliver, N. and Kuipers, E. (1996) Stress and Its Relationship to Expressed Emotion in Community Mental Health Workers, International Journal of Social Psychiatry, 42, p.150

Overall, J. and Gorham, D. (1962) The Brief Psychiatric Rating Scale. Psychological Reports, 10, p.799-812.

Paley, G. and Shapiro, D.A. (2002) Lessons from psychotherapy research for psychological interventions for people with schizophrenia. Psychology and Psychotherapy, 75, p.365-374.

Paul, G. L. and Lentz, R. J. (1977) Psychosocial treatment of chronic mental patients: Milieu vs. social learning programs. Cambridge: Harvard University Press. 
Paul, G. and Menditto, A. (1992) Effectiveness of inpatient treatment programs for mentally ill adults in public psychiatric facilities. Applied and Preventive Psychology, 1(1), p.41-63.

Penn, D., Hope, D., Spaulding, W., Nelson, C. and Sullivan, M. (1992) Behavioral correlates of ward behavior and symptomatology in schizophrenia. Paper presented at the Association for Advancement of Behavior Therapy, Boston.

Penn, D., Mueser, K., Spaulding, W., Hope, D. and Reed, D. (1995) Information processing and social competence in chronic schizophenia. Schizophrenia Bulletin, 21, p.269-281.

Penn, D., Spaulding, W., Reed, D., \& Sullivan, M. (1996). The relationship of social cognition to ward behavior in chronic schizophrenia. Schizophrenia Research, 20, p.327-335.

Penn, D., vander Does, J., Spaulding, W., Garbin, C., Linzen, D. and Dingamans, P. (1993). Information processing and social-cognitive problem solving in schizophrenia. Journal of Nervous and Mental Disease, 181, p.13-20.

Pfammatter, M., Junghan, U.M. and Brenner, H.D. (2006) Efficacy of Psychological Therapy in Schizophrenia: Conclusions From Meta-analyses Schizophrenia Bulletin, 32(suppl_1), p.S64-S80.

Pharoah, F.M., Mari, J.J., and Streiner, D. (2006) Family interventions in schizophrenia (updated 1995 Cochrane review). Cochrane Library.

Pilling, S., Bebbington, P., Kuipers, E., Garety, P., Geddes, J., Martindale, B., Orbach, G. and Morgan, C. (2002) Psychological treatments in schizophrenia: II. Meta-analyses of randomized controlled trials of social skills training and cognitive remediation. Psychology Medicine, 32(5), p.783-791.

Pratt, S. and Mueser, K. (2002) Social skills training for schizophrenia. In S. Hofmann \& M. Tompson (Eds.), Treating chronic and severe mental disorders: A handbook of empirically supported interventions. New York: Guilford.

President's New Freedom Commission on Mental Health (2004). Report to the President. Recovered from the internet 10/15/04 at http://www.mentalhealthcommission.gov/reports/reports.htm.

Rector, AT. and Beck, NA. (2004) Cognitive therapy of schizophrenia: a new therapy for the new millennium. American Journal of Psychotherapy, 54(3), p.291-300. 
Regier, D.A., Farmer, M.F., Rae, D.S., Locke, B.Z., Keith, S.J., Judd, L.L. and Goodwin, F.K. (1990) Comorbidity of mental disorders with alcohol and other drug abuse: results from the Epidemiologic Catchment Area (ECA) Study. Journal of the American Medical Association, 264, p.251-2518.

Renwick, S., Black, L., Ramm, M. and Novaco, R. (1997) Anger treatment for forensic hospital patients. Legal and Criminological Psychology, 2, p.103-116.

Samaan, M. (1975) Thought stopping and flooding in a case of auditory hallucinations, obsessions, and homicidal-suicidal behaviour. Journal of Behaviour Therapy and Experimental Psychiatry, 6, p.65-67.

Sensky, T., Turkington, D., Kingdon, D., Scott, JL., Scott, J., Siddle, R., O'Carroll, M. and Barnes, TR., (2000) A randomized controlled trial of cognitivebehavioural therapy for persistent symptoms in schizophrenia resistant to medication. Archives of General Psychiatry, 57(2), p.165-72.

Silverstein, S. M. and Wilkniss, S. M. (2004) At issue: The future of cognitive rehabilitation of schizophrenia. Schizophrenia Bulletin, 30(4), p.679-692.

Silverstein, S., Menditto, A. and Stuve, P. (2000) Shaping procedures as cognitive retraining techniques in individuals with severe and persistent mental illness. Psychiatric Rehabilitation Skills, 3, p.59-76.

Silverstein, S., Spaulding, W., Menditto, A., Savitz, A., Liberman, R., Berten, S. and Starobin, H (2008) Attention shaping: a reward-based learning method to enhance skills training outcomes in schizophrenia. Schizophrenia Bulletin, doi: 10.1093/schbul/sbm150.

Spaulding, W. D., Reed, D., Sullivan, M., Richardson, C. and Weiler, M. (1999) Effects of cognitive treatment in psychiatric rehabilitation. Schizophrenia Bulletin, 25(4), p.657-676.

Spaulding, W.D., Sullivan, M.E. and Poland, J.S. (2003) Treatment and Rehabilitation of Severe Mental IIIness, Guilford Press: New York.

Substance Abuse and Mental Health Services Administration (SAMHSA) (2004) Evidence-Based Practices: Shaping Mental Health Services Toward Recovery, http://mentalhealth.samhsa.gov/cmhs/communitysupport/toolkits.

Sullivan, H.F. (1962) Schizophrenia as a Human Process. W.W. Norton, New York.

Swanson J, Estroff S, Swartz M, et al (1997) Violence and severe mental disorder in clinical and community populations: the effects of psychotic symptoms, comorbidity, and lack of treatment. Psychiatry, 60, p.1-22. 
Tarrier, N. (1994) In Birchwood, M. and Tarrier, N. Psychological management of Schizophrenia, Chichester, Wiley.

Tarrier, N. (1987) An investigation of residual psychotic symptoms in discharged schizophrenic patients. British Journal of Clinical Psychology, 26 ( Pt 2), p.141-3.

Tarrier, N., Barrowclough, C., Haddock, G. and Wykes, T. (2002) Are all psychological treatments for psychosis equal? The need for CBT in the treatment of psychosis and not for psychodynamic psychotherapy. Psychology and Psychotherapy, 75, p.5-17.

Tarrier, N., Yusupoff, L., Kinney, C., McCarthy, E., Gledhill, A., Haddock, G. and Morris, J. (1998) Randomised controlled trial of intensive cognitive behaviour therapy for patients with chronic schizophrenia. British Medical Journal, 317(7154), p.303-7.

Taylor, J., Novaco, R., Gillmere, B., \& Thorne, I. (2002). Cognitive-behavioural treatment of anger intensity among offenders with mental retardation. Journal of Applied Research in Mental Retardation, 15, 151-165

Turner, S.M., Hersen, M. and Hellack, A.S. (1977) Generalization effects of social skills training in chronic schizophrenics: an experimental analysis.

Behaviour Research and Therapy, 14(6), p.391-8.

Twamley, E.W., Jeste, D.V. and Bellack, A.S. (2003) A review of cognitive training in schizophrenia. Schizophrenia Bulletin, 29(2), p.359-382.

Vaughn C.E., Leff, J. (1976) The influence of family and social factors on the course of psychiatric illness. British Journal of Psychology, 129, p.125-137.

Walker, E. (1994). Developmentally moderated expressions of the neuropathology underlying schizophrenia. Schizophrenia Bulletin, 20(3), p.453480.

Wing, J.K., Cooper, J.E. and Sartorius N (1974) The description and classfication of psychiatric symptoms. An instruction mannual for the PSE and CATEGO system. Cambridge University Press, Cambridge

Wong, S., Massel, H., Mosk, M. and Liberman, R. (1986) Behavioral approaches to the treatment of schizophrenia. In G. Burroughs, T. Norman and G. Rubenstein (Eds.), Handbook of studies on schizophrenia (p.79-100). Amsterdam: Elsevier Science Publishers.

Wykes, T. and C. Reeder (2005). Cognitive remediation therapy for 
schizophrenia: Theory and practice, London, Routledge.

Wykes, T., Steel, C., Everitt, B. and Tarrier, N. (2008) Cognitive behaviour therapy for schizophrenia: Effect sizes, clinical models and methodological rigour. Schizophrenia Bulletin, 34(1), p.523-537.

Xia, J. and Li, C. (2007) Problem solving skills for schizophrenia. Cochrane Database Syst Rev(2), CD006365.

Xiong, W., Phillips, M.R., Hu, X., et al. (1994) Family-based intervention for schizophrenic patients in China. A randomised controlled trial. British Journal of Psychiatry,165, p.239-247.

Yusupoff, L. and Haddock, G. (1998) Options and clinical decision making in the assessment and psychological treatment of hallucinations and delusions in in Perris, C. and McGorry, P. (Eds.) Cognitively-oriented psychotherapy in psychotic disorders, Chichester, Wiley.

Perris, C. and McGorry, P. (Eds.) Cognitively-oriented psychotherapy in psychotic disorders, Chichester, Wiley. 
Figure 1: Formulation of 'James'
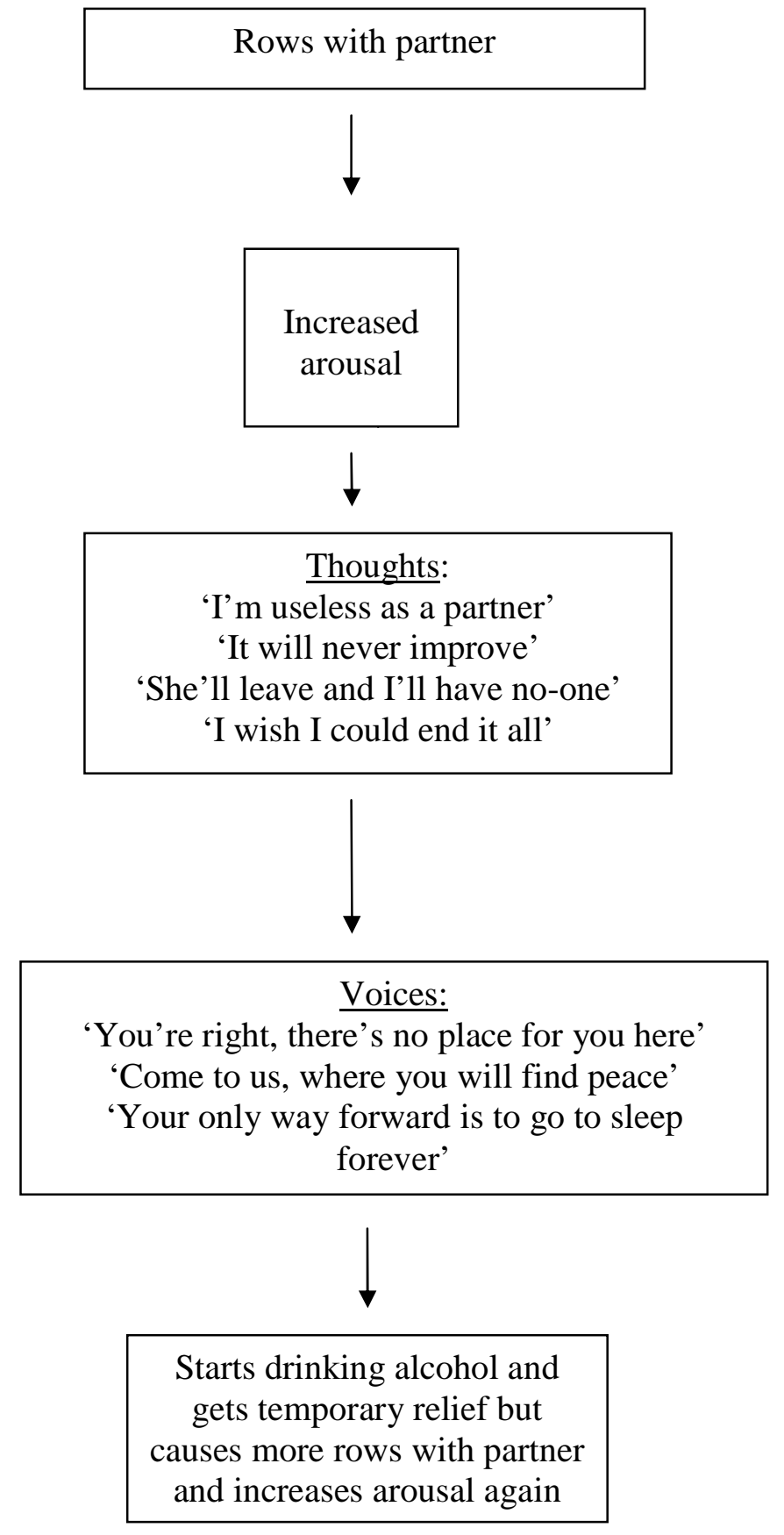
Figure 2: Keeping well traffic light

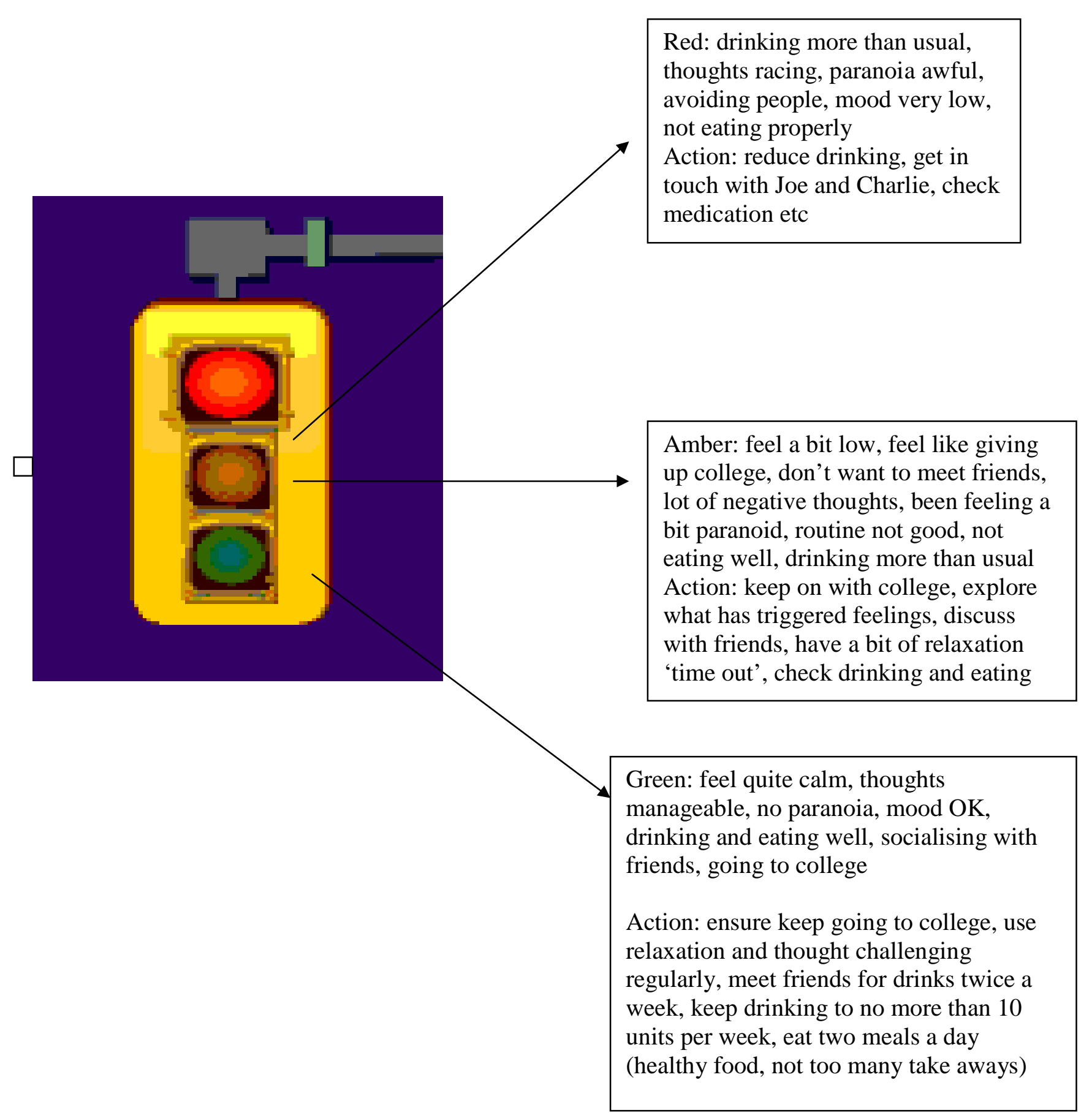


